\title{
Menopoz Dönemi Obez Kadınlarda Swanson Bakım Kuramının Kullanımı ve
}

\section{Hemşirelerin Rolü}

\author{
Özlem DOĞU KÖKÇÜ*, Sevcan KUTLUĞ**
}

\begin{abstract}
$\ddot{O} \mathbf{z}$
Menopoz, ovaryum aktivitesinin yitirilmesi sonucunda menstruasyonun kalıcı olarak sonlanmasıdır. Menopoz, fizyolojik bir olay olmasına rağmen birçok semptom ile karakterize olup kadın yaşamına önemli etkileri olan bir dönemdir. Menopoz dönemi ve obezite arasında güçlü bir ilişski vardır. Obezitenin menopoz dönemi kadınlarında görülen semptomların şiddetini arttırması ve bireyin yaşam kalitesini düşürmesiyle birlikte metabolik sendrom, diabetes mellitus, kardiyovasküler hastalıklar, meme ve endometrium kanseri gibi kronik hastalıklar için risk faktörü olması menopoz döneminde obez kadınlara verilecek hemşirelik desteğinin önemini arttırmaktadır. Swanson'un 1993 yıllında geliştirdiği kuram, bireyin kişiye özgü ve bütüncül bir psikososyal destek almasını, aldığı bakım sonucunda iyileşme sürecinin hızlanmasını, kendine olan güveni ve bağımsızlığının artmasını amaçlamaktadır. Ayrıca hemşirelerin bireyin yaşadığı zorlukları anlamaları ve bu zorlukları çözmeleri için bir rehber olacaktır. Bu sayede, hemşirelik sürecinde kuramın kullanılması menopoz dönemindeki obez kadınlarda bakımın sistematik ve etkin olmasını sağlamaktır. Bu derlemede; Swanson tarafından geliştirilen bakım kuramının hemşirelik tanıları kullanılarak menopoz dönemindeki obez kadınların bakımında kullanılabilirliği konusunda farkındalık yaratmak ve bu kuramın menepoz dönemindeki obez kadınların bakımına yol gösterici bir rehber olmasını sağlamak amacıyla yapılmıştır.
\end{abstract}

Anahtar Kelimeler: Menopoz, Obezite, Semptom, Swanson Bakım Kuramı, Hemşirelik Bakımı.

\begin{abstract}
The Use of Swanson Theory of Caring in Obese Women in Menopause and the Role of Nurses

Menopause is as the permanent termination of menstruation as a result of loss of ovarian functions. Although menopause is a physiological situation, it is characterized by many symptoms and has a significant impact on women's life. Obesity increases the severity of the symptoms in menopausal women, decreases the quality of life of the individual as well as a risk factor for chronic diseases, these situations increase the importance of nursing support to obese women during menopause. The theory developed by Swanson in 1993, an individual's personal and holistic psychosocial support, as a result of the care who received is aims to speed up the healing process and increase self-confidence and independence. It will also be a guide for nurses to understand difficulty lived of the in the individual's and solve these difficulties. Thus, the theory of nursing process in the care of menopausal obese women is to ensure systematic and effective use. In this respect; the aim of this review is to raise awareness by using nursing diagnoses about the availability of caring theory developed by Swanson for obese women during menopause and compile the theory of caring as a result of the literature review in the direction of the keywords in order to provide a guide for the care of the obese women during menopause.
\end{abstract}

Key Words: Menopause, Obesity, Symptom, Swanson Care Theory, Nursing Care.

Geliş tarihi: 26.10.2019 Kabul tarihi: 27.02.2021

$\mathrm{M}$ enopoz, ovaryum aktivitesinin yitirilmesi sonucunda menstruasyonun kalıcı olarak sonlanmasıdır (1). Menopoz dönemi; ilk semptomların görüldüğü premenopoz dönemi, en son âdet kanamasının görüldüğü menopoz dönemi ve menopozdan bir yıl sonra başlayıp yaşlılık dönemi başlangıcına kadar süren postmenopoz dönemi olmak üzere üç dönemden oluşmaktadır (2).

Menopoz, fizyolojik bir olay olmasına rağmen birçok semptom ile karakterize olup kadın yaşamına önemli etkileri olan bir dönemdir. Bu dönemde kadında sosyal yaşamdaki değiş̧ikliklerin yanı sıra hormonal değişiklikler de görülür. Hormonal değişikliklerde en önemli farklılık östrojen hormonu üzerinde gerçekleşir. Östrojen düzeyindeki azalışla birlikte fizyolojik ve psikolojik semptomlar da ortaya çıkar. Kadınlarda görülen semptomların şiddeti ve sıklığı döneme bağlı olarak değişebildiği gibi bireyden bireye de değişiklik gösterebilmektedir. Tüm bu değişiklikler sonucunda çeşitli sağlık sorunları ortaya çıkmakta ve kadının yaşamı olumsuz yönde etkilenmektedir (3).

Obezite, menopoz döneminde sıklıkla karşımıza çıkan bir durumdur. Menopoz dönemi kadın hayatında yönetilmesi gereken zorlu bir süreçken obezitenin de eklemesiyle süreç daha da karmaşık bir hal almaktadır. Obezitenin menopoz dönemi kadınlarında görülen semptomların şiddetini arttırması ve bireyin yaşam kalitesini düşürmesiyle birlikte Metabolik Sendrom, Diyabetes Mellitus, Kardiyovasküler Hastalıklar (4), Meme ve Endometrium Kanseri (5) gibi kronik hastalıklar için risk faktörü olması menopoz döneminde obez olan kadınlara verilecek hemşirelik desteğinin önemini arttırmaktadır.

$\mathrm{Bu}$ doğrultuda gözlemlenen ihtiyaca yönelik uygulanacak olan hemşirelik girişimlerinin daha etkin ve sistematik olması açısından Swanson bakım kuramı kullanılmasının fayda sağlayacağı düşünülmüştür. Bu derleme Swanson tarafinda geliştirilen bakım kuramının menopoz dönemindeki obez kadınların bakımında kullanılabilirliği konusunda farkındalık yaratmak ve bu kuramın menopoz dönemindeki obez kadınların bakımına yol gösterici bir rehber olmasını sağlamak amacıyla literatür ışı̆̆ında hazırlanmıştır. Literatür taraması anahtar kelimeler doğrultusunda son 10 yıl göz önüne alınarak CINAHL Plus, Cochrane, Ebsco, Science Direct, Pubmed, Ovid ve Google Akademi veri tabanları kullanılarak araştırmacılar tarafindan yapılmıştır.

Menopoz ve Obezite

Obezite dünyada olduğu gibi ülkemizde de hızla artmakta olan önemli bir sağlık problemidir (6). Dünya Sağlık Örgütü (DSÖ) 2018 verilerine göre Türkiye'de 16.092 .644 obez birey bulunduğunu ve $\% 29.5$ prevalans oranı ile Türkiye'nin, Avrupa'da obezitenin en fazla görüldüğü ülkeler arasında yer aldığını bildirmektedir (7).

* Sakarya Üniversitesi, Sağlık Bilimleri Fakültesi, Hemşirelik Esasları Anabilim Dalı, Sakarya, e mail: ozlemdogu@ sakarya.edu.tr ORCID: 0000-0003-1257-2551 ** Sakarya Üniversitesi, Sağlık Bilimleri Enstitüsü, Hemşirelik Anabilim Dalı, Sakarya, e mail: svenzcn@gmail.com ORCID: 0000-0003-1744-7872 


\section{Derleme}

Kadın yaşamında menopoz dönemi ve obezite arasında güçlü bir ilişki vardır. Literatürde de menopoz döneminde obezite prevelansının yüksek olduğu vurgulanmaktadır (6). Çayır ve ark. 2011 yılında yaptığı çalışmada menopozda olan kadınların \%41.0'ının, menopozda olmayanların ise \%29.7'sinin obez olduğu sonucuna ulaşmıştır. Çalışmadaki obezite oranları arasındaki farkın yüksek olması, östrojen eksikliğinin metabolizmayı yavaşlatarak obeziteye zemin hazırladığı düşüncesini ortaya koymaktadır (8). Menopoz döneminde obezite oranını saptamak amacıyla yapılan bir diğer çalışmada da kadınların \%43.0’ı fazla kilolu ve \%40.4'ü obez olarak saptanmıştır (9).

Literatür incelendiğinde obez olan ve obez olmayan kadınlar arasında menopoza girme yaşı ve yaşanılan semptomlar arasında belirgin farklar olduğu gözlenmektedir (10,11). Yapılan bir çalışmada obez kadınlarda depresif semptomlar, anksiyete, vazomotor semptomlar, uyku problemleri ve ciddi menopozal semptomların daha fazla görüldüğü sonucuna ulaşılmıştır (12). Obez kadınların büyük çoğunluğunda sedanter yaşam tarzının benimsenmesi nedeniyle kas eklem rahatsızlıkları ve kalp damar sistemine ait semptomların daha fazla görülmesi beklenmektedir. Trunson ve ark. 2011 yılında yaptıkları çalışmada literatürde elde edilen bulgulara karşıt olarak menopoz döneminde artan androjenin vücut yağında östrojene dönüşmesiyle birlikte yağ dokusunun östrojen kaynağı olduğunu ve bu durumun obez kadınlarda menopoz dönemi yaşanan vazomotor semptomların şiddetini azaltacağını öne sürmüşlerdir (13). Koyuncunun 2015 yılında yaptı̆̆ çalışma da bu bulguyu destekler niteliktedir. Çalışmaya göre obez olan ve olmayan kadınlar arasında menopoz semptomları sıklığı açısından bir fark bulunamamıştır. Literatürde bu bulguyu destekleyen başka çalışmalar da mevcuttur $(14,15)$.

Son yıllarda yapılan çalışmaların sonuçlarında gelişen teknolojinin getirdiği yaşam tarzı değişikliklerinin (sedanter yaşam, daha az çalışma, televizyon karşısında daha uzun vakit geçirme, hazır yemek yeme, yüksek kalorili gıdalar tüketme) sağlık davranışlarını olumsuz etkileyerek obezite oluşumunu arttırdığı görülmektedir (16). Menopoz döneminde obezite oluşumunu önlemek için sağlıklı beslenme ve normal vücut ağırlı̆̆ını korumanın yanı sıra düzenli egzersiz yapmak da son derece önemlidir (16). Düzenli yapılan fiziksel aktivitenin postmenopozal dönemdeki kadınlarda yaşam kalitesini iyileştirdiği saptanmıştır (17). Bu bilgiler doğrultusunda bireyin riskli sağlık davranışlarını değiştirmede uygulanacak olan hemşirelik bakımı yaşam kalitesini arttırma yönünde önemli bir etkiye sahiptir.

\section{Menopoz Dönemi Obez Kadınlarda Hemșire Desteğinin Önemi}

Günümüzde sağlık hizmetlerinin gelişmesi ve yaşam standartlarının gittikçe yükselmesi ile birlikte kadınların da yaşam süresi artmaktadır (18). DSÖ’nün yaptığı sınıflandırmaya göre yaş grupları 45-64 yaş grubu orta yaş, 65 yaş üzeri yaşlı nüfus, yaşlı nüfusta kendi içinde de alt gruplara ayrılmış olup 65-74 yaş grubu "genç yaşlı", 75-84 yaş grubu "ileri yaşlı", 85 ve üzeri yaş grubu ise "çok ileri yaşlı" olarak belirlenmiştir (19). Yaş grupları incelendiğinde menopoz döneminin kadın yaşamının önemli bir bölümünü oluşturduğu görülmektedir.

Menopoz döneminin sağlıklı geçirilebilmesi için iyi yönetilmesi gerekmektedir. Fakat Özer ve Gözükara'nın 2016 yılında yaptığı çalışma; menopoz dönemindeki kadınların birden fazla sisteme yönelik sorun yaşadıklarını ve yaşadıkları sorunlarla tek başlarına etkin baş edemediklerini ortaya koymuştur (20). Çalışmayla benzer sonuçlar gösteren diğer bir kaynakta, kadınların menopoz dönemi sorunları ve baş etme yollarına ilişkin yetersiz bilgiye sahip oldukları sonucuna varılmıştır (21). Menopoz dönemine ilişkin yapılan çalışmaların sonuç ve öneriler bölümünde hemşire desteğinin menopoz dönemindeki önemi ve gerekliliği yer almaktadır $(20,21)$.

Yaşam süresinin önemli bir dönemini oluşturan menopoz döneminde, bireyin yaşam kalitesinin korunması, sağlıklı bir yaşam sürebilmesi için fiziksel aktivite, egzersiz, dengeli beslenme ve kilo kontrolü yapılarak obezite ve obeziteye bağlı oluşan riskler azaltılabilmektedir (22). Bununla birlikte menopoz dönemine özgü değişimlere uyum sağlanabildiğinde sorunların hafiflediği görülmektedir (23). Hemşireler rehabilite edici rolleriyle bireyin yaşadığı döneme uyumunu sağlamak için gerekli eğitim ve danışmanlık vererek kaybolan fonksiyonları yeniden kazandırmayı, yaşadıkları semptomlarla baş etme becerilerini arttırmayı ve yaşam kalitesini yükseltmeyi hedeflemelidir (24). Bununla birlikte hemşire, bireyin kendi bakımını yönetmesini sağlamak amacıyla bağımsızlı̆̆ını güçlendirecek girişimleri planlanması gerekmektedir. Tüm bu hedefler ancak hümanistik ve holistik hemşirelik yaklaşımının model ve kuramlara dayandırılması ile gerçekleşebilir. Model veya kuramlara dayandırılmış hümanisitik ve holistik hemşirelik yaklaşımı bireye özgü bakıma olanak sağlayacak, hemşirelik mesleğini sistemli ve profesyonel bir şekilde uygulayarak iş merkezli olmaktan uzaklaştıracak, uygulanan bakımın amaçlı, sistematik ve etkin olmasını sağlamakla birlikte hemşirelerin ortak bir dil kurmalarına olanak tanıyarak bakımın kalitesini arttıracaktır (25).

\section{Menopoz Dönemi Obez Kadınlarda Swanson Bakım Kuramının Kullanımı}

Swanson'un 1993 yılında yaptığı Bakım Kuramı tanımı; insancıl yaklaşımı, bilimsel ve klinik bilgiyi, kişisel kültürel değerleri ve inançları kabul ederek, bireyin özgünlüğü ve yaşam deneyimlerinin önemi üzerinde durmaktadır (26,27). Kurama göre birey; kişiye özgü ve bütüncül bir psikososyal destek almalı (28) ve aldığı bakım sonucunda iyileşme süreci hızlanmalı, hemşireler bireyin yaşadığı zorlukları anlamalı, bireyin yaşadığı sorun çözülmeli ve kendine olan güveni ve bağımsızlığı artırılmalıdır (29). Kuramının uygulanması konusunda en temel noktanın çevre olduğunu düşünen Swanson, hastayı etkileyen durumları fark etmenin ve tanımlayabilmenin hastalığın iyileşmesinde önemli bir yere sahip olduğunu belirtmiştir $(26,30)$.

Swanson bakım kuramı bilmek, birlikte olmak, gereksinimlerini karşılamak, güçlendirmek, inancı korumak aşamalarını içeren beş basamaktan oluşmaktadır.

\section{Bilmek}

Bilmek, bir olayın kişinin hayatındaki önemini anlamaya çalışmaktır (31). Bilmek basamağının alt boyutlarında; birey üzerinde kurulan varsayımlardan kaçınma, bireyin değer verdiği noktaların merkezlenmesi, birey ve yaşadığı soruna dair ipuçları arama, elde edilen bilgileri değerlendirme, bakım veren ve alanın iç içe olması yer almaktadır. Bakım süreci hem bakım alan kişiyi hem de bakım verilen kişiyi kapsar (32). Bilmek, bakım sürecinin ilk adımı olup bireyi tanıma ve sorunları saptama yolunda en önemli aşamalardan biridir. 


\section{Derleme}

Hemşire bilmek aşamasında bireyden veri toplarken onun üzerinde kurduğu varsayımlardan kaçınarak kişiyi dikkatlice dinler ve sürekli olarak bireye ait ipuçları arar ve bunları değerlendirir. Hemşire, bireyi tanımaya gözlem, fizik muayene ve sağlık-hastalık öyküsünü alarak başlar. Bu aşamada hemşire, klinik deneyimi, bilgisi ve sezgileri doğrultusunda görüşme ve fizik muayene esnasında gözlem yapmalıdır. Menopoz döneminde bulunan obez bireyin öyküsünde öncelikle; bireysel özellikler (yaş, medeni durumu, eğitim durumu, mesleği, ekonomik durumu, eşinin yaşı, eğitim durumu ve mesleği, evlilik süresi), genel tıbbı öykü (Beden Kitle İndeksi (BKİ), sigara-alkol-madde kullanma durumu, beslenme alışkanlıkları, fiziksel aktivite yapma sıklığı, kronik hastalığa sahip olma ve sürekli kullandığ 1 ilaçlar), obstetrik ve jinekolojik özellikler (menarş ve ilk gebelik yaşı, doğum sayısı, menopoz yaşı ve menopoza girme şekli, menopoz dönemine yönelik bilgi düzeyi, menopoz dönemi yaşanılan sağlık sorunları ve sağlık kuruluşuna başvurma durumu, menopoz yakınmalarıyla baş etme teknikleri, destek faktörleri) ayrıntılı olarak sorgulanmalıdır (33).

\section{Birlikte Olmak}

Kuramın ikinci aşaması olan birlikte olmak, bireyin yanında olmak ve bireyle birlikte bir şey yapmak olarak tanımlanmaktadır (33). Birlikte olmak; bireyin neşe ya da üzüntü gibi hislerini paylaşmak, bireye değer vermek, onu sınırlandırmamak ve bireyin kazandığ 1 deneyimlerin farkına varması sürecidir $(26,30,32)$.

Hemşire; bireyin yaşadığı durumun her aşamasında yanında olmalı, güven ortamı sağlayarak yaşanılan durumun birey üzerindeki etkisinin paylaşılmasına olanak tanımalıdır (34). Bu aşamada hemşire menopoz dönemindeki obez bireyi daha iyi tanıyarak temel bakım gereksinimlerini belirlemeli ve öncelikler doğrultusunda verilecek bakımı planlamalıdır. Planlanan Bakımın içeriğinde menopoz dönemi görülen semptomlar, semptomlar ile baş etme yolları, obeziteye neden olabilecek davranışlar ve yaşam değişikliklerini kapsayan eğitim ve danışmanlık konuları yer almalıdır.

\section{Gereksinimlerini Karşılamak}

Swanson Kuramı’nın üçüncü aşaması bakım vericinin birey için elinden ne geliyorsa yapmasıdır (32). Gereksinimlerini karşılamak terapötik yöntemleri kapsayarak bireyin ihtiyaçlarını öngörebilmeyi, belirlenen ihtiyaçları kişinin saygınlığına zarar vermeden onu koruyarak ve konforunu arttırarak profesyonel bir şekilde yerine getirilmesini kapsar (34).

Hemşire planlanan hemşirelik girişimlerini gereksinimleri karşılama aşamasında bireyi kendi bakımına katarak uygulamaya başlar (26). Bakımın içeriğinde menopoz dönemi görülen semptomlar, semptomlar ile baş etme yolları, obeziteye neden olabilecek davranışlar ve yaşam değişikliklerini kapsayan eğitim ve danışmanlık konuları yer almalıdır. Menopoz dönemindeki obez bireylere verilen eğitim ve danışmanlık ile bireylerin bilgi düzeyleri arttırılarak yanlış inanç ve uygulamaları giderilir (33). Birey döneme özgü yaşayacağı semptomları ve baş etme yollarını kavrar. Bununla birlikte bireye obezite ile mücadelede fiziksel aktivite ve egzersiz programları, düzenli ve dengeli beslenme, kilo kontrolü sağlanması gibi konularda gerekli danışmanlık verilerek obezite ve obeziteye bağlı ortaya çıkabilecek riskler azaltılabilmektedir (35). Menopoz dönemindeki kadınlarda obezite ve dönemin getirdiği değişikler nedeniyle beden imajında bozulma ve benlik saygısında azalma görülmektedir. Hemşire, bireye destek olarak kendi gücünü fark etmesini sağlamalı ve bireyin öz saygısını geliştirmelidir (35).

Swanson Bakım Kuramı kapsamında menopoz dönemi obez kadınlarda belirlenen sorunlara ilișkin NANDA hemşirelik tanıları kitabı kullanılarak planlanan hemşirelik bakımının içeriğinde; bilgi eksikliği, gereksinimden fazla beslenme, beden imgesinde rahatsızlık, cinsel örüntülerde etkisizlik, konstipasyon riski, uyku örüntüsünde rahatsızlık hemşirelik tanıları yer almaktadır.

Hemşirelik tanısı: Bilgi eksikliği

Amaç: Bireyin menopoz dönemi ve obeziteyle ilgili bilgi eksikliğinin giderilmesi.

Girişimler: Bireyin menopoz dönemi ve obezite hakkındaki mevcut bilgi durumu belirlenir, soruları cevaplanır ve menopoz döneminde yaşanılan semptomlar, obezite nedenleri ve obezite ile mücadelede izlenecek yollar açıklanır (36-38).

Hemşirelik tanısı: Gereksinimden Fazla Beslenme

Amaç: Bireyin kilo alma riskine neden olan durumları, besin alımındaki artışın nedenlerini ve yaşam değişikliklerinin kilo kontrolü üzerindeki etkilerini tanımlaması

Girişimler: Bireyin BKI hesaplanır ve beslenme alışkanlığı öğrenilir. Kilo alımına neden olan faktörler bireyle birlikte tartış1lır (menopoz dönemi, düzensiz ve dengesiz beslenme, sedanter yaşam şekli, emosyonel durum, gelenek görenekler, kültürel ve kalıtsal faktörler vb.). Diyetisyen desteği ile gerekli öneriler ve sağlıklı yaşam davranışları öğretilir $(36,39,40)$.

Hemşirelik tanısı: Beden İmgesinde Rahatsızlık

Amaç: Kişi görünümünü kabul ettiğini gösterip bu durumu ifade etmesi.

Girişimler: Bireyin kendisi ile ilgili duygularını, düşüncelerini ve bakış açısını ifade etmesine olanak tanınır ve gerçekçi hedefler koyularak kilo vereceğine olan inancını sürdürmesi sağlanır. Bireyin baş etme durumunu güçlendirecek yakınlarıdestek sistemleri bakıma katılır $(38,40,41)$

Hemşirelik tanısı: Cinselliğin etkili olmaması

Amaç: Menopoz dönemi cinsel aktiviteye olan etkisini tanımlaması ve kabul etmesi, iletişimde ve ilişkide gelişim göstermesi, kabul edilebilir alternatif cinsel yaklaşımları tanımlar.

Girişimler: Yaşadığı sorunu ifade etmesi ve soru sorması için birey cesaretlendirilir, yaşadı ğı endişeleri partneri ile paylaşması konusunda desteklenir. Bireye menopoz dönemindeki hormonal değişikliklerin cinsel aktiviteye olan etkisi açıklanır ve stres durumunu azaltmak için düzenli egzersizin fiziksel ve psikososyal yararları öğretilir $(36,37,42)$.

Hemşirelik tanısı: Konstipasyon Riski

Amaç: Kişi her 2-3 günde bir bağırsak hareketlerinin ve dışkı çıkışı olduğunu bildirmesi.

Girişimler: Konstipasyonu değerlendirmek amacıyla bağırsak alışkanlıklarına ilişkin günlük tutması önerilir. Dengeli bir diyet, S1vı tüketimi ve düzenli yapılan egzersizin önemi anlatılır $(39,41)$.

Hemşirelik tanısı: Uyku Örüntüsünde Rahatsızlık 
Derleme

Amaç: Bireyin uyumayı inhibe eden ya da etkileyen faktörleri ve uyku getiren faktörleri tanımlaması.

Girişimler: Uykuyu etkileyen faktörlere yönelik rahatlatıcı önlemler alınır (Örneğin; menopoz döneminde görülen sıcak basması için 1lık duş alma, ince kıyafetler giyme gibi yöntemler bireye öğretilir). Düzenli yatma ve kalkma saatleri oluşturularak, uykuya hazırlık için gevşemeyi sağlayan bir rutin (Örneğin; bitki çayı, masaj, 1lık duş) oluşturulur (39,40,43).

\section{Güçlendirme}

Güçlendirme, yeni bir olay ile karşılaşan bireyin öz bakım gücünü geliştirerek baş etmesini kolaylaştırma aşamasıdır. Bu aşama bireye duygusal destek sunmakla birlikte verilen bilgi ve açıklamalar sonucunda geri bildirim alınarak bireyin endişelerine odaklanmaya, etkin baş etme yollarını öğrenmeye ve bunları kullanmaya yardım etmeyi kapsar (32).

Hemşire, güçlendirme aşamasında bireyin menopoz döneminde yaşadığı sorunların etkisini hafifletmek için uğraşmalı (44) ve bu dönemi atlatmasına yardım etmelidir (29). Menopoz dönemindeki obez kadınların tam bir iyilik hali içerisinde olması için bu döneme yönelik yanlış inanç ve algılamaların düzeltilmesi, menopoz dönemine ait sorunlarla baş etme yollarını öğrenmesi ve öğrendiği baş etme yollarını kullanabilmesi amaçlanmaktadır (45). Aynı zamanda bireyler sağlık durumlarının tedavisi ile ilgili uygun tercihleri yapabilmeli, menopoz dönemi ortaya çıkabilecek sağlık sorunlarını önleme ve sorunlarla baş etmede sağlık kuruluşuna başvurabilme becerisini kazanmış olmalıdır.

\section{Inanci Korumak}

Kuramın son aşaması olan inancı korumak bakımın temelinde yer almaktadır (26). Kişinin yaşadığı bir süreci atlatması için gereken güce sahip olduğunu bilmek, bireye inanmak ve inancını sürdürmeyi sağlamak olarak tanımlanmaktadır $(26,34,44)$. Swanson, bakım veren hemşirelerin bireyin ümitsiz olduğu anlarda bile güven ve ilham vermesi gerektiğini ve bireye gerçekçi bir iyimserlikle yaklaşması gerektiğini vurgulamaktadır $(26,38,46)$. Hemşire inancı koruma aşamasında bireye güvenip ona inanmalı, destekleyici bir tutum ile bireye yaklaşarak bireyin çaresiz olmadığını fark etmesini sağlamalı ve bireyin durumu atlatması için gerekli inancı kazanıp sürdürmesine destek olmalıdır (34).

\section{Sonuç}

Menopoz dönemi kadın yaşamında fizyolojik bir süreçken obezite son yıllarda hızla artan bir sağlık problemidir. Obezitenin menopoz dönemine eklenmesiyle süreç karmaşık bir hal almakta ve sürecin yönetilmesi daha da zorlaşmaktadır. Konuyla ilgili yapılan taramalar sonucunda kadınların bu sürece ait yeterli bilgiye sahip olmadıkları ve bu dönemi etkin yönetemedikleri sonucuna ulaşılmıştır. Bu sonuç doğrultusunda menopoz dönemi obez kadınlara verilecek hemşirelik desteği büyük önem kazanmıştır. Swanson Bakım Kuramı hemşirelik süreciyle birebir ilişkili olması nedeniyle menopoz dönemindeki obez kadınlarda kullanımı uygundur. Swanson Bakım Kuramı birey ve bakım vericinin birbirini tanımasına ortam hazırlarken planlanan hemşirelik girişimlerinin uygulanmasını da kolaylaştıracaktır. Kuramın hemşirelik bakımında uygulanması bakım vericilerin ortak bir dil kurmasını ve verilen bakımın kalitesinin artmasını sağlayacaktır. Literatürde Swanson Bakım Kuramı'nın menopoz dönemindeki obez kadınlara uygulandığı bir çalışma henüz görülmemiştir. Bu nedenle gelecekte Swanson Bakım Kuramı kullanılarak menopoz dönemindeki obez bireylere verilecek bakımın etkinliğine yönelik yapılacak çalışmaların sayısı arttırılması ve yapılan çalışmaların sonuçlarının klinik uygulamalara yansıtılması önerilmektedir.

\section{Bilgilendirme}

Fikir/kavram ÖDK; tasarım ÖDK; denetleme/danışmanlık ÖDK; kaynak taraması ÖDK, SÖ; makalenin yazımı ÖDK, SÖ.

\section{Kaynaklar}

1. Özcan H, Oskay Ü. Menopoz döneminde semptom yönetiminde kanıta dayalı uygulamalar. Göztepe Tıp Dergisi. 2013;28(4):157-163.

2. Sherman S. Defining the menopausal transition. Am J Med. 2015;118(12):3-7.

3. Demirci H, Kökkaya D. Klimakterik dönemdeki kadınlarda algılanan sosyal desteğin menopozal tutum ve yakınmalar üzerine etkisi. 3. Uluslararası Bilim Sempozyumu; 5-8 Eylül 2018; Pristina-Kosovo.

4. Chopra SM, Misra A, Gulati S, Gupta R. Overweight, Obesity and related non-communicable diseases in asian indian girls and women. Eur J Clin Nutr. 2013;67: 688-696.

5. Smith H. Obesity and its complications in women. S Afr Pharm. J. 2012;79(10):26-30.

6. Çayır A, Atak N, Köse SK. Beslenme ve diyet kliniğine başvuranlarda obezite durumu ve etkili faktörlerin belirlenmesi. Ankara Üniversitesi Tıp Fakültesi Mecmuası. 2011;64(1):13-19

7. Obezite Tanı ve Tedavi Kılavuzu. Türkiye Endokrinoloji ve Metabolizma Derneği. Miki Matbaacılık San. ve Tic. Ltd. Şti. Ankara; 2018. 25tbl_gruplar144108.pdf

8. Aydın Y, Celbek G, Kutlucan A, Önder E, Güngör A, Alemdar R. ve ark. Batı karadeniz bölgesinde obezite prevelansı: melen çalışması. Turkish Journal of Endocrinology and Metabolism. 2012;16:52-57.

9. Tuna F. Postmenopozal kadınlarda obezite oranları ve kemik mineral yoğunluğu düzeyleri. Manisa Celal Bayar Üniversitesi Sağlık Bilimleri Enstitüsü Dergisi. 2019;6(1):3-7.

10. AlQuaiz J, Siddiqui A, Tayel S, Habib F. Determinants of severity of menopausal symptoms among saudi women in riyadh city. Climacteric. 2014;17(1):71-78.

11. Im EO, Ko Y, Chee W. Ethnic differences in the clusters of menopausal symptoms. Health Care For Women Int. 2014;35(5):549-565.

12. Blümel JE, Chedraui P, Aedo S, Fica J, Mezones HE, Barón G. Obesity and its relation to depressive symptoms and sedentary lifestyle in middle-aged women. Maturitas. 2015;80(1):100-105. 
Derleme

13. Thurston RC, Sowers MR, Chang Y, Sternfeld B, Gold EB, Johnston JM. et al. Adiposity and reporting of vasomotor symptoms among midlife women: the study of women's health across the nation. Am J Epidemiol. 2008;167(1):78-85.

14. Chim H, Tan BHI, Ang CC, Chew EMD, Chong YS, Saw SM. The prevalence of menopausal symptoms in a community in singapore. Maturitas. 2002;41(4):275-282.

15. İnceboz Ü, Demirci H, Özbaşaran F, Çoban A, Nehir S. Factors affecting the quality of life in climacteric women in manisa region, Balkan Med J. 2010;27(2):111-116.

16. Baltacı G. Obezite ve egzersiz. Türkiye Halk Sağlı̆̆ı Kurumu, Obezite Diyabet ve Metabolik Hastalıklar Dairesi Başkanlığı. 2012; 11-79.

17. Bal MD, Şahin NH. The effects of personality traits on quality of life, Menopause. 2011;18(12):1309-1316.

18. Özgür G, Yıldırım S, Komutan A. Menopoz sonrası kadınların öz bakım gücü ve etki eden faktörler. Anadolu Hemşirelik ve Sağlık Bilimleri Dergisi. 2010;13(1):35-43.

19. World Health Organization. Proposed working definition of an older person in africa for the mds project. Geneva; 2002. URL: https://www.who.int/healthinfo/survey/ageingdefnolder/en/

20. Özer Ü, Gözükara F. Şanlıurfa'da kadınların menopozla ilgili yaşadıkları sorunların baş etme yollarının ve bakış açılarının belirlenmesi. Hacettepe Üniversitesi Hemşire Fakültesi Dergisi. 2016;3(1):16-26.

21. Dinçer Y, Oskay Ü. Menopoz döneminde kadınların cinsellik ile ilgili sorunlarının incelenmesi: kalitatif bir çalışma. Kadın Sağlığı Hemşireleri Dergisi. 2018;4(2):16-28.

22. Küçükkelepçe DŞ, Yılmaz S. Kadın hayatının her evresinde; obezite. Kadın Sağlığı Hemşireliği Dergisi. 2018;1(4):548.

23. Çelik AS, Pasinlioğlu T. Klimakterik dönemde yaşanan semptomlar ve hemşirenin rolü. Erciyes Üniversitesi Sağlık Bilimleri Fakültesi Dergisi. 2013;1(1):48-56.

24. Kaya M. Kadın sağlı̆̆ında güncel yaklaşımlar ve hemşirenin rolü. II. Uluslararası Katılımlı Kadın \& Sağlık Kongresi; 1316 May1s 2013; Sakarya.

25. İşbir GG, Mete S. Hemşirelik bakımında model kullanımına bir örnek: bulantı kusma sorunu olan bir gebenin roy uyum modeline göre incelenmesi. DEUHFED [online].2009;2(2):75-86. URL:https://docplayer.biz.tr/11871185-Deuhyo-ed2009-2-2-75-86-hemsirelikte-model-kullanimina-ornek-75.html

26. Swanson KM. Nursing as informed caring for the well-being of others. J Nurs Scholarsh.

1993;25(4):352-357.

27. Wojnar DM. Caring. İçinde Peterson S, Bredow TS, Middle range theories: application to nursing research. 2. Edition. Wolters Kluwer Health; 2009: 190-193.

28. Murphy F, Philpin S. Early miscarriage as 'matter out of place: an ethnographic study of nursing practice in a hospital gynaecological unit. Int J Nurs Stud. 2010;47(5):534-541.

29. Jansson C, Adolfsson A. Application of "swanson's middle range caring theory" in sweden after miscarriageınt. Int J Clin Med. 2011;2(2):102-109.

30. Adolfsson A. Metaanalysis to obtain a scale of psychological reaction after perinatal loss: focus on miscarriage. Psychol Res Behav Manag. 2011;4:29-39.

31. Andershed B, Olsson K. Review of research related to kristen swanon's middle-range theory of caring, Scand J Caring Sci. 2009;23(3):598-610.

32. Swanson KM. Empirical development of a middle range teory of caring. Nurs Res. 1991;40(3):161-166.

33. Albay H, Kaplan S. Menopozal dönem yaşam kalitesini nasıl etkiliyor? Ankara Sağlık Bilimleri Dergisi. 2015;4(1):1-24.

34. Karaca PP, Oskay ÜY. Düşük yapan kadınların bakımında swanson bakım kuramı. Hemşirelikte Eğitim ve Araştırma Dergisi. 2017;14(3):228-232.

35. Dedeli Ö, Fadıloğlu Ç. Obezitede güçlendirme ve hemşirelik yaklaşımları. Türkiye Klinikleri Hemşirelik Bilimleri Dergisi. 2012;4(2):94-101.

36. Moyet LJC. Hemşirelik tanıları el kitabı. 3. basım. Erdemir F. Nobel Tıp Kitap Evi Ltd. Şti.; 2012:105-481.

37. Ackley BJ, Ladwig GB. Nursing Diagnosis Handbook: An Evidence-Based Guide to Planning Care. New York:Tenth Edition. Elsevier; 2014:25-245.

38. Birol L. Hemşirelik Süreci. 10. Basım. Akademisyen kitapevi; 2016:35-646.

39. İlhan SE, Ançel G, Yönt GH. Hemşirelik tanıları, girişimleri, sonuçları. 1. Baskı. Andaç Yayınları; 2017:191-453.

40. Scully N, Wilson D. Fundamentals Of Nursing. Elsevier Sağlık Bilimleri. 2014:2-163.

41. Acaroğlu R, Kaya H. Hemşirelik Tanıları Tanımlar ve Sınıflandırma 2018-2020. 11.Baskı. İstanbul, Nobel Tıp Kitabevleri; 2020:30-544.

42. Wilkinson JM, Barcus L, Pearson Hemşirelik Tanıları El Kitabı. 1.Baskı. Kapucu S, Akyar İ, Korkmaz F. Pelikan Yayınlar1; 2018:21-978.

43. Phelps LL, Ralph SS, Taylor CM. Hemşirelik Tanıları Referans El Kitabı. 10. Baskı. Karahan A, Kav S, Güneş Tıp Kitapevleri; 2019:15-406.

44. Ahern LD, Corles IB, Davis SD, Kwong JJ. Infusing Swanson's theory of caring into an advanced practice nursing model for an infectious diseases anal dysplasia clinic. J Assoc Nurses AIDS Care. 2011;22(6):478-488.

45. Çetin ÖE, Eroğlu K. Menapoz dönemindeki kadınların yaşadıkları sorunlar ve baş etme yollar1.DEUHFED[online].2015;8(4):219-225. URL:http://deuhyoedergi.org/index.php/DEUHYOED/article/view/215. 06 Kasim 2019

46. Smith MC, Parker ME. Nursing theories and nursing practice. İçinde Swanson KM, Kristen Swanson's Theory of Caring. 4. Edition. F.A. Davis Company; 2015:521-531. 